\title{
TAKING OUR LEARNING AND TEACHING STRATEGY TO THE NEXT LEVEL THROUGH TECHNOLOGY ENHANCED CAMPUS DEVELOPMENT
}

\author{
Alastair D. Robertson \\ Abertay University (UNITED KINGDOM)
}

\begin{abstract}
Over the last three years Abertay University has radically evolved its strategy for teaching and supporting learning. This paper outlines Abertay's journey over the last few years, including the key features of our new pedagogic approach and its impact so far. For example, in 2016 Abertay was the highest ranked modern Scottish University in the National Student Survey (NSS) and shortlisted for the prestigious Times Higher Education "University of the Year" award.

In order to further enhance our students' progression, attainment and employability we have recognized the need to invest further in two key (and related) areas: technology enhanced learning and estate development in order to create a so-called "sticky campus" i.e. somewhere our students will want to come and stay. This has included full implementation of electronic management of assessment (EMA); blended learning; new technology-rich collaborative learning environments and science laboratories which promote richer student-staff interactions and new ways of learning; and a planned complete refurbishment of the University library which will provide a variety of learning environments (formal and informal) from summer 2017.
\end{abstract}

The paper will detail the drivers for these changes; the change management processes involving a staff-student partnership involving management, academic and professional services; successes; challenges; lessons learned and future plans.

Keywords: Curriculum reform, assessment, learning spaces, technology.

\section{INTRODUCTION}

Abertay is a modern University with a long history of educating students and preparing them for the world of work. Established in 1888 as the Dundee Technical Institute, it's primary purpose was vocational education. Since achieving University title in 1994, the courses have always been designed to develop confident, independent, employable graduates. It offers a wide range of courses in fields as diverse as psychology, ethical hacking ${ }^{1}$, forensic science, business, civil engineering and sports across four academic Schools and has an international reputation in the fields of computer games technology (the only European institution in the top 50 of the 2016 Princeton Review), computer arts, environmental management and biotechnology. Community engagement is an important aspect of the university's mission and it has strong links with its two local partner colleges leading to a high number of students (approximately one third of entrants in 2016/17) entering with advanced standing into years two and three of the four year undergraduate programmes.

Despite the breadth of portfolio, the Unversity is comparatively small in size, with approximately 4000 undergraduate students and a little over 200 academic staff across the four Schools.

\subsection{Drivers for Change}

The arrival of a new Principal, Professor Nigel Seaton in 2012, following a period of turbulence, followed by a number of key senior management appointments, including myself as Director of Teaching and Learning Enhancement (TLE) in April 2013, catalysed a period of transformational change and systemic reforms across the institution. The drivers for these changes included the evolving global context, changes to university funding (particularly in England), increased student diversity, advances in technology, internationalisation, increasing demands from learners and policymakers for increased flexible degree pathways and choice and the need for the University to remain competitive sustainably.

${ }^{1}$ Abertay was first in the UK to offer this, at the time. 
In light of these changes and following my arrival, the University decided to go back to first principles and rethink its pedagogic approach. The resulting review and consultation process, involving all of the key internal stakeholders including the Executive, managers, academic and professional services staff and students, took around 8 months with University Senate approving the new TLE strategy in December 2013.

\section{ABERTAY'S TLE STRATEGY}

The University's 2015-20 strategic plan outlines three key purposes [1]:

- to offer transformational opportunities to everyone who has the ability to benefit from Abertay's approach to university education;

- to inspire and enable our students, staff and graduates to achieve their full potential;

- to use our knowledge and expertise to have a positive impact on the world around us.

The TLE strategy that has been developed is very short (around 850 words) but is action focused and has been designed to catalyse transformational change. A full account of the TLE strategy and the associated change management approach has been published elsewhere [2], what follows is a brief synopsis. A short video has also been produced by the University of the Abertay student learning experience [3]. The three strategic priorities and associated key features of our new pedagogic approach are as follows:

1 Reforming our curriculum to revolutionise the delivery and design of our programmes, which will advance students' knowledge; enhance students' preparedness for post-graduation and the world of work; and that recognises and facilitates different modes of learner journey.

Features include:

- New programmes offer increased flexibility and student choice (from 2016/17)

- A suite of new interdisciplinary electives for years one and two of all programmes (from 2016/17)

- Move from 15 to 20 credit modular structure (from 2016/17)

- A suite of seven new accelerated degrees (from 2016)

- New academic calendar including mid-term feedback weeks (from 2014/15)

2 Incentivising students' performance through a new integrated approach to all aspects of assessment (formative, summative and recording achievement) with a focus on programme level learning outcomes, joint Honours/ Grade Point Average (GPA) degree classification and implementation of the Higher Education Achievement Report (HEAR) [4] for 2014-15 entrants.

Features include:

- New assessment principles, policy and practice to support deeper student learning (from 2014/15)

- New literal grading scale and implementation of Grade Point Average (GPA) for degree awards (from 2014/15)

- Implementation of the HEAR to recognise students' wider achievements (from 2014/15)

3 Raising the status of teaching in the institution in terms of: leadership, professional recognition, reward and development by developing a holistic, staff-centred approach to learning and teaching CPD from 2014-15.

Features include:

- Staff centred approach to academic professional development

- Professional recognition CPD scheme aligned to all four descriptors of the UK Professional Standards Framework for teaching and supporting learning in higher education (UKPSF) [5]

- Support for scholarly communities of practice including seminars, workshops, resources, blog, new funding scheme for teaching and learning innovation 


\section{CHANGE MANGAGEMENT}

There are three quite remarkable factors regarding the transformational changes to Abertay's pedagogic approach over the last three years. These are first of all, the extent of change; we have redesigned our curricula, our assessment policy and practices and invested significantly in staff development. Secondly, the pace of the implementation of these changes- we effectively have gone for a big bang-type approach. Thirdly, a key feature of our change management approach has been involving key stakeholders including managers, academic staff, professional services and students, not just in terms of consultation but actually involving them in the formulation of policy through townhouse type meetings, workshops and short life task groups e.g. on our new Abertay Attributes and Electronic Management of Assessment (EMA).

The approach which we have taken for all of our academic reforms and which we have now embedded across the University is summarised in terms of a framework involving 5 "P" prompts [5]:

- What is the Purpose? What is the policy trying to achieve/ why is it needed?

- What are the Principles? The policy should have a set of up to 10 underlying principles e.g. for our new assessment policy two of the principles for assessment and feedback should a) improve student learning and b) be inclusive, equitable, consistent and appropriate.

- What does this mean in practice? Practices and processes should not counter the principles.

- Participation? Who are the key stakeholders and how will they be engaged in the change process?

- Pace? What is the timescale for implementation of the new policy, what are the milestones, how will it be evaluated?

\section{IMPACT}

\subsection{Student Satisfaction}

Despite the very short timescale of the implementation of the new TLE strategy, there is already significant evidence of positive impact. In terms of student satisfaction, as measured through the National Student Survey (NSS), Abertay has gone from 82-88\% overall satisfaction and in 2016 was the highest scoring modern University in Scotland. Satisfaction has gone up in every category including teaching, assessment and feedback, academic support, organization and management, learning resources and personal development. The rise in student satisfaction around Assessment and Feedback in particular have been considerable. Comparing NSS 2013- 2016:

- q.7 "feedback on my work has been prompt" rose from $44 \%$ to $70 \%$

- q.8 "I have received detailed comments on my work" rose from $57 \%$ to $74 \%$

- q.9 "feedback on my work has helped me clarify things I did not understand" rose from $54 \%$ to $70 \%$.

This points to the positive impact of the new Assessment policy (implemented 2014-15) which stipulates a 10 working day for feedback on in-module assignment (15 working days for end of module assignments). Another important factor in the rise of student satisfaction with assessment and feedback has been the implementation in 2015-16 of EMA which is a system for students electronically submitting assignments and receiving feedback from academic staff. This required some investment from the University in terms of additional hardware for staff (such as two screens, tablet computers etc) but also in terms of staff development as it has required significant upfront time from a number of our staff to change their assessment practices e.g. develop rubrics, familiarisation with hardware and software as well as, in some cases, more fundamental changes to actual assignments. EMA and the greater use of technologies has opened up new opportunities for delivering teaching and supporting student learning.

\subsection{Student Attainment}

In terms of other evidence of impact, we have seen an increase in students achieving good grades at all levels, particularly since the new grading scale was introduced in 2014/15. The new scale was designed to enhance simplicity, consistency and provide a series of accompanying qualitative 
descriptors for each grade that staff and students could relate to. Illustrative data for stage 1 and stage 4 are provided below. It is important to note that the increase in good modular grades and good degrees $\left(1^{\text {st }}\right.$ and 2.1$)$ is due to enhancements in our learning, teaching and assessment policies and practices as well as an increase in student entrance requirements.

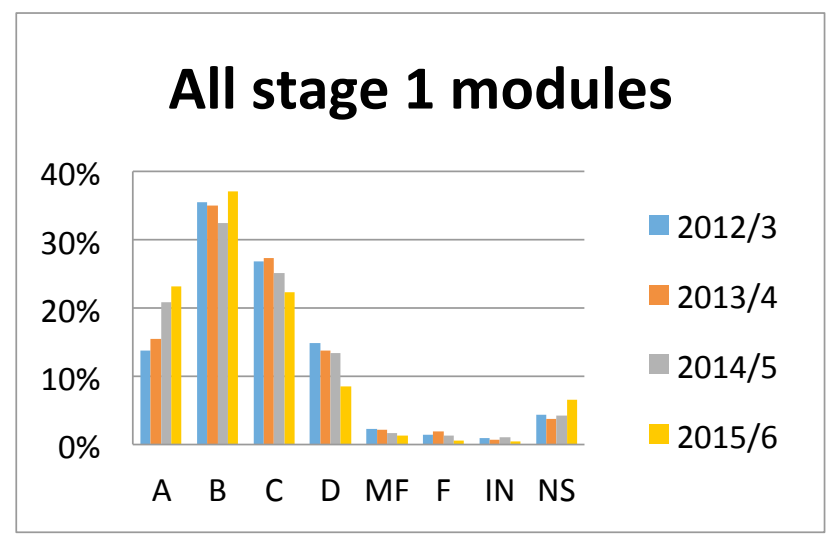

Figure 1. Student grades for all stage 1 modules. 2012/13-2015/16.

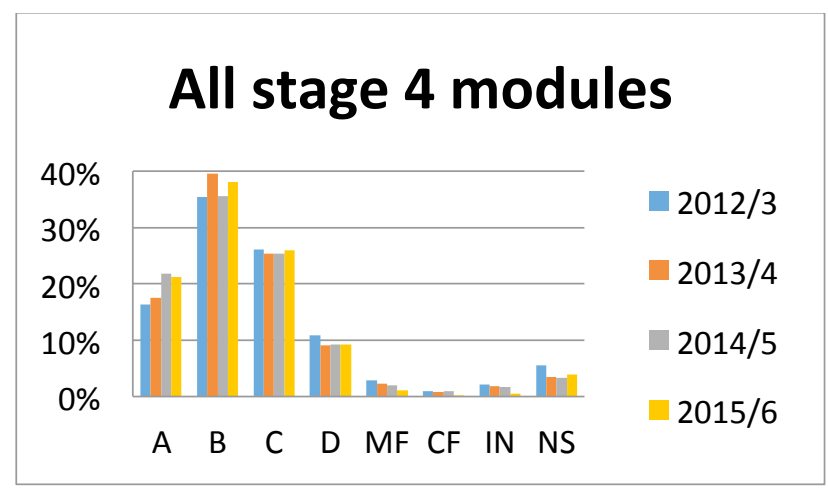

Figure 2. Student grades for all stage 4 modules. 2012/13- 2015/16.

\subsection{Professional Recognition of Staff}

The University has set a stretching target for the national professional recognition of staff who teach; the 2015-20 strategic plan states that: "By 2020 we will ensure all staff involved in teaching and supporting learning achieve national professional commitment". It is a condition of successful probation that all new academic staff successfully complete the University's PG Cert in HE Teaching which leads to Fellowship of the Higher Education Academy (HEA). As part of the TLE strategy, a new holistic CPD scheme has been developed into which the PG Cert HET is integrated and which aligns fully with the four descriptors of the UK Professional Standards Framework for teaching and supporting learning (UKPSF) [6]. Numbers of staff with HEA recognition have increased significantly going from 2 AFHEA and 34 FHEA in 2012/13 to 5 AFHEA, 66 FHEA, 17 SFHEA and 2 PFHEA which represents approximately $40 \%$ of the academic staff population. A further 50 staff are currently engaged in either the PG Cert HET or Going for Gold so these numbers are set to increase significantly over the next 12 months.

\section{THE "STICKY" CAMPUS}

What is quite remarkable about Abertay's success is the limited amount of direct resource (other than staff time) which has been required to successfully implement these wide ranging changes. The University is not, however, complacent and recognises that in order to further enhance our students' progression, attainment and employability we need to invest further in two key (and related) areas: technology enhanced learning and estate development in order to create a so-called 'sticky campus' i.e. somewhere our students will want to come and stay [7]. The direction of travel for campus development at Abertay is informed by the following additional trends which are being observed across the HE sector: 
- Solutions should be pedagogic-led rather than estates-led or technology-led. The right pedagogic model is fundamental, technology and estates then play a critical role to create the right environment which support new pedagogic approaches.

- More active, collaborative learning environments lead to higher student engagement and better learning outcomes. Active learning environments are not as space efficient as, say, lectures i.e. the room's capacity is reduced, however, overall space utilisation is better i.e. it is used more by students for informal learning outside of class time. The trend seems to be creating spaces for 40-60 students.

- Lecture theatres still have a place but there is a trend towards creating spaces with low angle seating tiers, seating in groups with tables, curved set ups which may be used in didactic or collaborative learning modes. Lighting can be controlled by the lecturer and might include spotlights on particular tables as they report back.

- Technology is key. Trends include improved connectivity and power to enable "bring your own device", "flipped classroom" (active learning), online and blended learning, lecture capture (especially short video summaries rather than full blown lecture recording) and learning analytics. Interactive smartboards are excellent tools to promote collaboration and creativity between instructor and students or in team meetings.

- Notion of well-being leading to better productivity/ better learning. This includes a number of environmental factors such as air quality, lighting, temperature, acoustics and smell! Also the need to factor in spaces which facilitate brief interactions/ chance meetings, circulation routes through buildings, areas which promote collaboration and flexibility of set-ups.

So, what are the implications for Abertay and how is the University responding? An important distinguishing feature of the Abertay student experience is the relatively small cohorts and, consequently, class sizes which allow richer staff-student interaction and support (Abertay is ranked in the top 20 in the UK for student support according to the 2016 Whatuni Student Awards). The most common module size in the range of $11-20$ students, $80 \%$ of all 491 modules running in 2016/17 have fewer than 60 students and only about $6 \%$ have more than 100 students. An audit in 2016 of the teaching estate revealed a space utilization of around $26 \%$ therefore the challenge has not been one of a lack of space more one of lacking the right kind of space.

\subsection{Current Campus Developments}

In 2013 the University completed its $£ 2,864,000$ ICT Transformation Programme. The programme included four main projects which are Classroom AV Technology; End User Computing; Network Infrastructure and Security; and Storage Backup and Servers. In 2014 and 2015, the University spent $£ 4.2 \mathrm{M}$ on maintenance, renewing and refurbishing multi-use flexible space and several other projects most notably a new Graduate School and Support Enquiry Zone (SEZ) in the library which is a one stop shop for student enquiries.

In recognition that there was an urgent need to develop new teaching spaces which aligned more with the philosophy of our new T and L strategy, several projects were approved for 2016/17. These include a new Collaborative Learning Suite (£200k) completed in September 2016 which provides a technology-rich, flexible space usable by students outwith formal class contact; new wet labs for teaching and research in sciences, food and nutrition (£3.5M, completion January 2017); and plans to completely refurbish the university library with new study areas, social learning spaces, integrated student support hub etc (cost, £4.5M, completion by September 2018).

\subsubsection{Change management approach}

The Director of TLE working closely with the Head of Estates, Director of Information Services and Registrar (timetabling) was tasked by the University Executive to review new learning spaces in early 2016. A decision had already been made to develop new science teaching labs but plans were at a very early stage. Early consultation with staff and students was seen as vital and an open invitation workshop entitled "Rethinking our Learning Environment" was held in March 2016 which was attended by around 50 colleagues. Participants were encouraged to do some blue sky thinking about what they would like to see at Abertay in the future and what current challenges they faced. A raft of helpful ideas and creative suggestions were made and a small steering group involving TLE, Estates, Information Services, Registry, the Student Association and a couple of academic staff was set up to develop ideas further. The group agreed the following five key principles for future development: 
Involve stakeholders

2 Develop leading edge spaces which are accessible and which will genuinely enrich student learning

3 Look externally

4 Develop a variety of spaces over the next few years which are pathfinders for possible wider implementation in the University i.e. not a one size fits all approach.

5 Harness the potential of modern technologies.

\subsubsection{Progress, to date}

1 Better IT infrastructure to support "bring your own device". Wifi coverage is now $100 \%$ (it was previously around $90 \%$ but with some notable gaps). New investment in IT infrastructure for staff and students is comprising more power sockets and workstations (screen, keyboard and docking station for laptops) and reducing the number of fixed desktop PCs. An on campus laptop short term loan service based in the library where students can book out a charged laptop is under consideration and is already in use in some other Universities e.g. Sheffield Hallam University, Maynooth University etc.

2 Collaborative Learning Suite. This facility is designed to provide a flexible, technologically-rich environment for around 30 students and is aimed specifically at supporting collaborative learning amongst students and creating much more interaction between the staff educator and their students. Pictures and plans of the room are available on the Abertay TLE blog [8]. Around 20 staff have volunteered from all Schools and following training have been encouraged to share practice and learning. This area is very much a prototype "sand pit", it is not perfect and already minor improvements are planned. At least two more similar spaces are planned in the next 12 months and the learning from this pilot is proving vital information. A key aim of the initiative is to build capacity and expertise in the University around technologically-rich collaborative based learning environments.

3 Wet labs. Science lab refurbishments are now complete and feature state of the art technologies to permit student collaboration and interaction with peers and the instructor e.g benches are in islands which feature a large screen at each end where the lecturer or any student can connect their devices to share information. Similarly, the lecturer can teach from any point in the laboratory rather than being fixed to a point at the front of the class. Adjoining social learning spaces have also been developed to attract students and staff to keep working and sharing in the vicinity of the labs. A social area at the end includes two collaborative desks along with soft furnishings and a small kitchen area. Even the circulation spaces are filled with opportunities to interact, whether it's a seat to chat or a place to charge your phone. As part of the new Food and Drink laboratories, an area has been built for product testing which will be used by the University but also on a commercial lease basis by local businesses.

4 Technologies to promote student engagement in and out of the classroom. The University has a well-established VLE (Blackboard), however, this is not designed to support in-class interaction. Testing is underway with several software options which aim to enhance student engagement and formative interaction between lecturers and their students. Examples include "Bluepulse", "Top hat" and a new forthcoming JISC Blackboard student app. Drivers are: improved student attendance, progression and attainment and a drop in response rates to module surveys since moving to an online only system.

5 Dedicated online learning, recording facilities. To support the move towards enhancing the University's capacity for blended and online learning, several recording areas are planned equipped with AV, multiple cameras etc for delivery of distance learning, micro $\mathrm{MOOC}^{2} \mathrm{~s}$ etc. These are required as staff are predominantly in open plan offices which are not conducive to record resources/ learning materials, vod/ podcasts etc.

6 Staff development and support is recognised as key to the success of this initiative. As well as involving staff in the design of new spaces, significant resource has been dedicated to supporting them with technological hard ware/ software but also in terms of thinking about new ways of teaching and supporting learning. A range of workshops, training and 1-2-1 support sessions have been run and learning objects developed. Amongst the group of academic

\footnotetext{
${ }^{2}$ Massive Open Online Courses (MOOCs)
} 
volunteers there is an emerging community of practice and an enthusiasm to support "novices" as use of the new spaces becomes more widespread.

\subsection{Planned Campus Developments}

The following priority areas have identified for the next stages of our campus development:

\subsubsection{Space utilisation}

As stated above, space utilisation is currently around $26 \%$, according to a recent audit. A task group led by Estates supported by Registry and TLE has been established to review current space utilisation, opportunities for rationalisation, reconfiguring of existing spaces (given the nature of module sizes etc.) and commercialisation opportunities for out of hours' usage etc. Review of the existing timetabling system is also an important part of the group's remit.

\subsubsection{Library refurbishment}

A complete refurbishment of the library is underway with works planned for summer 2017. The idea is to create a fully integrated student support hub where all central student support services (including library, disability, counselling, career development and academic support) will be co-located. The library will offer a range of new study areas to accommodate students' different learning styles, a new working café, IT training suites and a creative design space which will support formal and informal learning, project planning and design thinking. Significant attention is being paid to environmental factors (lighting, temperature, acoustics, furnishings), flexibility of space and functionality for users to bring their own devices (including power sockets, wireless connectivity).

\subsubsection{Sharing good practice}

As this is an emergent area for the University as a whole, and for many of our staff in particular, we are on a rapid learning curve. Lessons are already being learned and as staff and students become more familiar with the new spaces and technologies, so it is important to share good practice, both internally and externally. A number of Universities in the UK are at a similar stage of development and there is an appetite in the sector to learn from others as evidenced by the popularity of last year's Digital Classroom Roadshow which is planned again for 2017 [9]. There are opportunities for not only AV professionals to share practice but also academic staff at the discipline level and this is something Abertay is keen to explore further.

\section{CONCLUSIONS}

This case study has outlined how a small, modern University in Scotland has responded to the global challenges faced by higher education in a way that is appropriate to our context and purpose. Significant progress has been made but the University is in no way complacent. Some key learning points for us are as follows:

- Change management, involving staff and students as partners, is essential for successful strategy development and implementation. If hearts and minds are not won over, sustainable change cannot occur.

- Doing what is right for your University and your students and not being afraid of being "different". External benchmarks such as NSS and the new Teaching Excellence Framework (TEF) are important but should not drive institutional behaviour. Rather, improving students' learning and attainment in efficient and effective ways has to be the priority and everything else will follow.

- Technology and campus development are key to creating the right learning environments for engaging and retaining our students and helping them to achieve their potential.

- New ways of teaching and supporting learning are opening up which are proving challenging to our staff and students and causing us to rethink our curricula and assessments.

- We are, and always will be, on a learning journey, supporting innovation and horizon scanning for future opportunities 


\section{ACKNOWLEDGEMENTS}

I would like to thank Abertay's Principal (Professor Nigel Seaton) and Vice Principal Academic (Professor Steve Olivier) for their continued support, guidance and inspiration.

\section{REFERENCES ${ }^{3}$}

[1] http://www.abertay.ac.uk/media/strategic\%20plan\%202015\%20for\%20web.pdf

[2] A.D. Robertson, "Developing a new whole institutional approach to Teaching and Learning Enhancement", Higher Education Academy, 2016.

[3] http://www.abertay.ac.uk/studying/learning-experience/

[4] http://www.hear.ac.uk

[5] https://www.heacademy.ac.uk/ukpsf

[6] S. Olivier, "How to manage rapid change", Times Higher Education, 2015.

[7] See for example, https://student-strategy.uq.edu.au/

[8] https://abertaytle.wordpress.com/collaborative-learning-suite/

[9] http://www.digitalclassroomroadshow.co.uk/

${ }^{3}$ All websites accessed 19 January 2017 